\title{
Ibio-Number Assay and Erythropoietin Bioactivity: Comparison of the Calculated and the Stated Potencies of the Biological Reference Preparations of Erythropoietin
}

\section{Hermentin P}

Feuerdornweg 8, 35041 Marburg, Germany

*Corresponding author: Hermentin P, Feuerdornweg 8, 35041 Marburg, Germany, ph: +49 6420 82090; E-mail: peter.hermentin@t-online.de

Received date: March 16, 2017; Accepted date: March 30, 2017; Published date: April 26, 2017

Copyright: (c) 2017 Hermentin P, et al. This is an open-access article distributed under the terms of the Creative Commons Attribution License, which permits unrestricted use, distribution, and reproduction in any medium, provided the original author and source are credited.

\begin{abstract}
The potencies of the biological reference preparations of erythropoietin, assigned by the European Pharmacopoeia Commission on the basis of the normocythaemic and polycythaemic mouse bioassay for erythropoietin, have retrospectively been calculated by the author via the Ibio-number assay, a physicochemical assay based on capillary zone electrophoresis data that allows to calculate the potency of erythropoietin medicinal products.
\end{abstract}

The retrospective analysis by the author of the capillary electrophoresis data of three collaborative studies published in 2004, 2007 and 2015 has revealed that the potencies assigned for erythropoietin reference preparations batch 1 and batch $2(\sim 130.0 \mathrm{IU} / \mathrm{\mu g}$, each) have been stated $\sim 5 \%$ too low respectively $\sim 10 \%$ too low, whereas the potency stated for erythropoietin reference preparation batch $3(\sim 141.1 \mathrm{IU} / \mu \mathrm{g})$ was confirmed (difference to the stated potency $=-1.2 \%$ ) and therefore free of doubts.

Thus, erythropoietin medicinal products that have been calibrated against erythropoietin reference preparation batch 1 or batch 2 have been subject to the same error which was, however, within the error of the mouse bioassay and therefore not crucial.

With respect to erythropoietin concentrated solution batch release according to the European Pharmacopoeia, the very broad criteria for erythropoietin identification via capillary zone electrophoresis (which is based on broad ranges defined for the various erythropoietin isoforms) could be replaced by a single and quite narrow lbio-number range, which would provide a significant increase in assay precision and accuracy and hence in drug safety.

Moreover, the Ibio-number assay could be a candidate physicochemical assay to replace the mouse bioassay in the quality control of erythropoietin batch release.

Keywords Bioactivity; Bioassay; Biological reference preparation; Capillary zone electrophoresis; Erythropoietin; Potency

\section{Abbreviations}

BRP: Biological Reference Preparation; cBRP: Candidate BRP; CRS: Chemical Reference Substance; cCRS: candidate CRS; CV: Coefficient of Variation; CZE: Capillary Zone Electrophoresis; EDQM: European Directorate for the Quality of Medicines; EPO: Erythropoietin; Ibionumber: Isoform number calculated via the peak numbering in CZE; in: Individual isoform number shares; IS: International Standard; IU: international unit; MV: Mean value; NIBSC: National Institute for Biological Standards and Control; Ph. Eur.: European Pharmacopoeia; pn: Peak area percent shares; ref(s): Reference(s)

\section{Introduction}

Recombinant human erythropoietin is a biotechnologically produced hormone which stimulates human red blood cell growth and is therefore marketed worldwide for the treatment of anemia. The biological activity of the erythropoietin medicinal products is determined via in vivo assays in mice which are known to be highly inaccurate $(\mathrm{CV} \approx 25 \%[1,2], \approx 20 \%[3,4]$; uncertainty $15-30 \%$ [5] as stated by Zimmermann et al. [3]). Therefore, there are ongoing efforts to replace the highly contested (consumption of animals) and highly variable polycythaemic and normocythaemic mouse bioassays in the quality control of erythropoietin by more precise and more accurate physicochemical methods.

One of these proposed alternatives is the Ibio-number assay [6], a physicochemical assay based on the CZE data gathered according to Ph. Eur. [7], which has been shown to predict the bioactivity of EPO medicinal products with high precision and accuracy [6].

In principle, the assay has already been introduced in $2006[8,9]$, however has only recently been termed as such [6], when the assay was applied to calculate the potencies of various EPO drug substance and drug product samples, including the candidate EPO biological reference preparation batch 3 .

Whereas the "Ibio-number assay" [6] uses the bioactivity of EPO isoforms for potency calculation, the "I-number assay" [10] (another alternative physicochemical assay) uses the peak numbering of EPO isoforms for bioactivity calculation and is calibrated against the stated 
Citation: Hermentin P (2017) Ibio-Number Assay and Erythropoietin Bioactivity: Comparison of the Calculated and the Stated Potencies of the Biological Reference Preparations of Erythropoietin. Pharm Anal Acta 8: 542. doi:10.4172/2153-2435.1000542

Page 2 of 12

bioactivity of EPO BRP3, the potency of which - in contrast to EPO BRP1 and EPO BRP2 - was without any doubt [11].

The current "Ibio-number" study in a way parallels the "I-number" study reported elsewhere [11] as it is based on the same set of CZE data gathered in various collaborative studies designed to establish EPO BRP1 [12], EPO BRP2 [13], EPO BRP3 [14] and the EPO chemical reference substance [15]. However, the current study extends its scope to EPO BRP batch 4 [16] and to the WHO 3rd International Standard for Erythropoietin, recombinant, for bioassay (11/170) [17].

\section{Materials and Methods}

\section{Materials}

EPO BRP1, cBRP2, BRP2, cBRP3, BRP3 and cCRS were as described in collaborative studies published in 1997 [12], 2004 [13], 2007 [14] and 2015 [15], and the CZE data were taken from the latter three studies. In each of these studies, the (c)BRPs consisted in 50:50 (weight / weight) blends of epoetin-alpha and epoetin-beta. The stated potencies of BRP1 and BRP2 were 32,500 IU/vial, each, where each vial contained approximately $250 \mu \mathrm{g}$ EPO [12,13], equivalent to 130,000 $\mathrm{IU} / \mathrm{mg}$ or $130.0 \mathrm{IU} / \mu \mathrm{g}$. The stated potency of BRP3 was $35,280 \mathrm{IU} / \mathrm{vial}$, where each vial contained approximately $250 \mu \mathrm{g}$ EPO [14], equivalent to $141,120 \mathrm{IU} / \mathrm{mg}$ or $141.1 \mathrm{IU} / \mu \mathrm{g}$.

EPO BRP batch 4 again was an epoetin $\alpha / ß$ 1:1 mixture - with a stated potency of $13000 \mathrm{IU} /$ vial [16]. "This batch was prepared with the same (for EPO- $\beta$ ) or similar (for EPO- $\alpha$ ) starting materials, carrier buffer and production process as were used to produce the BRP 3 but with a lower content, i.e. around $100 \mu \mathrm{g}$ of EPO per vial instead of 250 $\mu \mathrm{g} /$ vial for BRP3" [16].

The 3rd WHO International Standard for Erythropoietin, recombinant, for bioassay (NIBSC code: 11/170) contains 1650 IU per ampoule, where each ampoule contains approximately $11 \mu \mathrm{g}$ of recombinant human EPO from the USA [17].

\section{Methods}

The Ibio-numbers of these EPO materials were calculated as earlier described [6]: "Ibio is defined as the sum of the products of the individual CZE peak area percent shares (pn) of the EPO isoforms ( $\mathrm{n}=$ 1-8) and isoform factors Fi corresponding with the respective isoform bioactivities [8,9] (Formula $1[6])$ :

Ibio $=\mathrm{p} 1 \times \mathrm{F} 1+\mathrm{p} 2 \times \mathrm{F} 2+\mathrm{p} 3 \times \mathrm{F} 3+\mathrm{p} 4 \times \mathrm{F} 4+\mathrm{p} 5 \times \mathrm{F} 5+\mathrm{p} 6 \times \mathrm{F} 6+$ $\mathrm{p} 7 \times \mathrm{F} 7+\mathrm{p} 8 \times$ F 8 Formula 1

For epoetin alfa and epoetin beta, the factors Fi were derived from the bioactivities of the individual isoforms as published by Amgen for epoetin alfa [18] (providing Ibio_A) (Tables 1a-5a) respectively Roche for epoetin beta [19] (providing Ibio_R) (Tables 1b-5b). The final Ibionumber was the arithmetic mean of Ibio_A and Ibio_R (cp. Tables $1 \mathrm{c}-5 \mathrm{c})$. As the isoform bioactivities were published as "units/mg erythropoietin polypetide" [18] respectively "IU/mg protein" [19], the 'primary' Ibio-numbers were "multiplied by the factor 0.60 polypetide/mg erythropoietin glycoprotein to give specific activities expressed as units/mg erythropoietin glycoprotein" [18] respectively the 'final' Ibio-numbers. Isoforms 1-8 (where applicable) were used for Ibio-number calculation [6].

Ibio-number calculation for CBRP3 was described in details elsewhere [6]. The Ibio-numbers of BRP1, cBRP2, BRP2, BRP3 and cCRS were calculated alike from the CZE data provided in the corresponding collaborative studies [13-15], which is shown in Tables $1-5$.

The Ibio-numbers retrospectively calculated by the author from the CZE data of these studies were used to assess the inter-laboratory precision of the assay. The accuracy of the assay was determined by relating the calculated Ibio-numbers to the stated bioactivities of the BRPs set $100 \%$, each.

\begin{tabular}{|c|c|c|c|c|c|c|c|c|c|c|c|c|c|c|}
\hline \multirow[t]{2}{*}{ Peak No. } & \multicolumn{2}{|c|}{$\begin{array}{l}\text { Amgen } \\
\text { polypeptide }\end{array} \quad \mathrm{IU} / \mathrm{\mu g}$} & \multicolumn{2}{|c|}{ Lab 2} & \multicolumn{2}{|c|}{ Lab 3} & \multicolumn{2}{|c|}{ Lab 8} & \multicolumn{2}{|c|}{ Lab 9} & \multicolumn{2}{|c|}{ Lab 10} & \multicolumn{2}{|c|}{ Lab 11} \\
\hline & & Factor & $\mathrm{pn}$ & in & pn & in & pn & in & pn & in & pn & in & pn & in \\
\hline 1 & 50.3 & 0.50 & 0.4 & 0.2 & 0.8 & 0.4 & 1.0 & 0.5 & 0.8 & 0.4 & 0.8 & 0.4 & 1.0 & 0.5 \\
\hline 2 & 70.6 & 0.71 & 1.9 & 1.3 & 2.5 & 1.8 & 3.1 & 2.2 & 2.2 & 1.6 & 2.4 & 1.7 & 2.7 & 1.9 \\
\hline 3 & 96.6 & 0.97 & 5.9 & 5.7 & 6.0 & 5.8 & 6.9 & 6.7 & 5.6 & 5.4 & 6.2 & 6.0 & 6.2 & 6.0 \\
\hline 4 & 170.3 & 1.70 & 18.4 & 31.3 & 18.3 & 31.2 & 17.8 & 30.3 & 19.1 & 32.5 & 17.7 & 30.1 & 19.0 & 32.4 \\
\hline 5 & 255.8 & 2.56 & 29.6 & 75.7 & 29.0 & 74.2 & 28.2 & 72.1 & 30.1 & 77.0 & 28.8 & 73.7 & 28.8 & 73.7 \\
\hline 6 & 258.4 & 2.58 & 28.7 & 74.2 & 27.9 & 72.1 & 27.5 & 71.1 & 24.4 & 63.0 & 28.5 & 73.6 & 27.8 & 71.8 \\
\hline 7 & 258.7 & 2.59 & 14.4 & 37.3 & 14.2 & 36.7 & 14.1 & 36.5 & 16.1 & 41.7 & 14.6 & 37.8 & 13.7 & 35.4 \\
\hline 8 & 205.8 & 2.06 & 0.7 & 1.4 & 1.3 & 2.7 & 1.4 & 2.9 & 1.8 & 3.7 & 0.9 & 1.9 & 0.8 & 1.6 \\
\hline \multicolumn{3}{|c|}{ Ibio_A_primary = } & \multicolumn{2}{|c|}{227.1} & \multicolumn{2}{|c|}{224.8} & \multicolumn{2}{|c|}{222.2} & \multicolumn{2}{|c|}{225.3} & \multicolumn{2}{|l|}{225.2} & \multicolumn{2}{|c|}{223.3} \\
\hline \multicolumn{3}{|c|}{ Ibio_A_final = } & \multicolumn{2}{|c|}{136.3} & \multicolumn{2}{|c|}{134.9} & \multicolumn{2}{|c|}{133.3} & \multicolumn{2}{|c|}{135.2} & \multicolumn{2}{|l|}{135.1} & \multicolumn{2}{|c|}{134.0} \\
\hline \multicolumn{3}{|c|}{ Mean Ibio $A=134.8 \pm 1.0$} & $C V=0$ & & & & & & & & & & & \\
\hline
\end{tabular}

Table 1a: BRP1 Ibio-number calculation and inter-laboratory precision. CZE data derived from Table 3a of Behr-Gross et al. 2004 [13] - Isoform distribution (in \%) of BRP1, using isoform bioactivities published by Amgen [18]. 
Citation: Hermentin P (2017) Ibio-Number Assay and Erythropoietin Bioactivity: Comparison of the Calculated and the Stated Potencies of the Biological Reference Preparations of Erythropoietin. Pharm Anal Acta 8: 542. doi:10.4172/2153-2435.1000542

Page 3 of 12

\begin{tabular}{|c|c|c|c|c|c|c|c|c|c|c|c|c|c|c|}
\hline \multirow[t]{2}{*}{ Peak No. } & \multirow{2}{*}{$\begin{array}{l}\begin{array}{l}\text { Roche IU/ug } \\
\text { protein }\end{array} \\
\#)\end{array}$} & \multirow[b]{2}{*}{ Factor } & \multicolumn{2}{|c|}{ Lab 2} & \multicolumn{2}{|l|}{ Lab 3} & \multicolumn{2}{|c|}{ Lab 8} & \multicolumn{2}{|c|}{ Lab 9} & \multicolumn{2}{|c|}{ Lab 10} & \multicolumn{2}{|c|}{ Lab 11} \\
\hline & & & pn & in & pn & in & pn & in & pn & in & pn & in & pn & in \\
\hline 1 & 19 & 0.19 & 0.4 & 0.1 & 0.8 & 0.2 & 1.0 & 0.2 & 0.8 & 0.2 & 0.8 & 0.2 & 1.0 & 0.2 \\
\hline 2 & 40 & 0.40 & 1.9 & 0.8 & 2.5 & 1.0 & 3.1 & 1.2 & 2.2 & 0.9 & 2.4 & 1.0 & 2.7 & 1.1 \\
\hline 3 & 75 & 0.75 & 5.9 & 4.4 & 6.0 & 4.5 & 6.9 & 5.2 & 5.6 & 4.2 & 6.2 & 4.7 & 6.2 & 4.7 \\
\hline 4 & 150 & 1.50 & 18.4 & 27.6 & 18.3 & 27.5 & 17.8 & 26.7 & 19.1 & 28.7 & 17.7 & 26.6 & 19.0 & 28.5 \\
\hline 5 & 200 & 2.00 & 29.6 & 59.2 & 29.0 & 58.0 & 28.2 & 56.4 & 30.1 & 60.2 & 28.8 & 57.6 & 28.8 & 57.6 \\
\hline 6 & 280 & 2.80 & 28.7 & 80.4 & 27.9 & 78.1 & 27.5 & 77.0 & 24.4 & 68.3 & 28.5 & 79.8 & 27.8 & 77.8 \\
\hline 7 & 400 & 4.00 & 14.4 & 57.6 & 14.2 & 56.8 & 14.1 & 56.4 & 16.1 & 64.4 & 14.6 & 58.4 & 13.7 & 54.8 \\
\hline 8 & 205.8 & 2.06 & 0.7 & 1.4 & 1.3 & 2.7 & 1.4 & 2.9 & 1.8 & 3.7 & 0.9 & 1.9 & 0.8 & 1.6 \\
\hline \multicolumn{3}{|c|}{ Ibio_R_primary = } & \multicolumn{2}{|c|}{231.5} & \multicolumn{2}{|l|}{228.7} & \multicolumn{2}{|l|}{226.0} & \multicolumn{2}{|c|}{230.5} & \multicolumn{2}{|c|}{230.0} & \multicolumn{2}{|l|}{226.3} \\
\hline \multicolumn{3}{|c|}{ Ibio_R_final = } & \multicolumn{2}{|c|}{138.9} & \multicolumn{2}{|c|}{137.2} & \multicolumn{2}{|c|}{135.6} & \multicolumn{2}{|c|}{138.3} & \multicolumn{2}{|c|}{138.0} & \multicolumn{2}{|c|}{135.8} \\
\hline \multicolumn{3}{|c|}{ Mean Ibio_R $=137.3 \pm 1.4$} & \multicolumn{2}{|c|}{$C V=1.0 \%$} & 6) & & & & & & & & & \\
\hline
\end{tabular}

Table 1b: Using isoform bioactivities published by Roche [19].\#) Specific activity of isoform peak no. 8 as published by Amgen [18] as the specific activity of this isoform of Roche [19] was not available.

\begin{tabular}{|c|c|c|c|c|c|c|c|c|}
\hline \multicolumn{2}{|c|}{ Lab no. } & 2 & 3 & 8 & 9 & 10 & 11 & cp. Table 1a \\
\hline \multirow{3}{*}{ BRP1 } & A & 136.3 & 134.9 & 133.3 & 135.2 & 135.1 & 134.0 & \\
\hline & $\mathrm{R}$ & 138.9 & 137.2 & 135.6 & 138.3 & 138.0 & 135.8 & \multirow{2}{*}{ cp. Table $1 \mathrm{~b}$} \\
\hline & Mean & 137.6 & 136.1 & 134.5 & 136.7 & 136.5 & 134.9 & \\
\hline
\end{tabular}

Table 1c: Mean of means. A: Ibio-numbers calculated using isoform factors deduced from ref [18], R: Ibio-numbers calculated using isoform factors deduced from ref [19].

Outliers according to Grubbs [20] respectively Dixon [21], as retrospectively identified by the author in the collaborative studies upon Ibio-number calculation, are specified in footnotes to the Tables and disregarded in the current study.

As no CZE data were communicated for EPO BRP batch 4, the Ibionumber of EPO BRP batch 4 was regarded identical to the Ibionumber of EPO cCRS, as these two materials were prepared from the same batch produced at the NIBSC, UK, in 2012 [16].
As, likewise, no CZE data were available for the 3rd IS, which consists of epetin alfa, the epoetin alfa secondary standard from Centocor was used, the CZE data of which have been gathered in a kind of limited validation (determination of repeatability and intermediate precision) [22]; the corresponding Ibio-number calculation has been published elsewhere [6].

\begin{tabular}{|c|c|c|c|c|c|c|c|c|c|c|c|c|c|c|c|c|}
\hline \multirow[t]{2}{*}{$\begin{array}{l}\text { Peak } \\
\text { No. }\end{array}$} & \multirow[t]{2}{*}{$\begin{array}{l}\text { Amgen IU/ug } \\
\text { polypeptide }\end{array}$} & \multirow[b]{2}{*}{ Factor } & \multicolumn{2}{|c|}{ Lab 2} & \multicolumn{2}{|c|}{ Lab 3} & \multicolumn{2}{|c|}{ Lab 8} & \multicolumn{2}{|c|}{ Lab 9} & \multicolumn{2}{|c|}{ Lab 10} & \multicolumn{2}{|c|}{ Lab 11} & \multicolumn{2}{|c|}{ Lab 12} \\
\hline & & & pn & in & pn & in & pn & in & pn & in & pn & in & pn & in & pn & in \\
\hline 1 & 50.3 & 0.50 & & & & & 0.3 & 0.2 & 0.5 & 0.3 & 0.4 & 0.2 & 0.3 & 0.2 & 0.2 & 0.1 \\
\hline 2 & 70.6 & 0.71 & 1.0 & 0.7 & 1.0 & 0.7 & 1.6 & 1.1 & 0.9 & 0.6 & 1.3 & 0.9 & 1.5 & 1.1 & 1.0 & 0.7 \\
\hline 3 & 96.6 & 0.97 & 4.5 & 4.3 & 4.9 & 4.7 & 5.1 & 4.9 & 3.8 & 3.7 & 4.6 & 4.4 & 5.2 & 5.0 & 5.3 & 5.1 \\
\hline 4 & 170.3 & 1.70 & 16.8 & 28.6 & 16.8 & 28.6 & 16.2 & 27.6 & 17.3 & 29.5 & 15.4 & 26.2 & 19.0 & 32.4 & 17.3 & 29.5 \\
\hline
\end{tabular}


Citation: Hermentin P (2017) Ibio-Number Assay and Erythropoietin Bioactivity: Comparison of the Calculated and the Stated Potencies of the Biological Reference Preparations of Erythropoietin. Pharm Anal Acta 8: 542. doi:10.4172/2153-2435.1000542

Page 4 of 12

\begin{tabular}{|l|l|l|l|l|l|l|l|l|l|l|l|l|l|l|l|l|}
\hline 5 & 255.8 & 2.56 & 27.1 & 69.3 & 27.2 & 69.6 & 26.3 & 67.3 & 27.8 & 71.1 & 26.8 & 68.6 & 28.7 & 73.4 & 26.9 & 68.8 \\
\hline 6 & 258.4 & 2.58 & 30.4 & 78.6 & 29.7 & 76.7 & 30.0 & 77.5 & 29.4 & 76.0 & 30.4 & 78.6 & 30.0 & 77.5 & 29.6 & 76.5 \\
\hline 7 & 258.7 & 2.59 & 18.6 & 48.1 & 18.3 & 47.3 & 18.6 & 48.1 & 18.6 & 48.1 & 19.2 & 49.7 & 15.2 & 39.3 & 18.1 & 46.8 \\
\hline 8 & 205.8 & 2.06 & 1.7 & 3.5 & 2.1 & 4.3 & 1.8 & 3.7 & 1.8 & 3.7 & 1.9 & 3.9 & 0.1 & 0.2 & 1.7 & 3.5 \\
\hline Ibio_A_primary $=$ & & 233.2 & 232.0 & 230.4 & 232.9 & 232.5 & 229.1 & 231.0 \\
\hline Ibio_A_final $=$ & 139.9 & 139.2 & 138.2 & 139.8 & 139.5 & 137.4 & 138.6 \\
\hline Mean Ibio_A $=138.9$ & \pm \\
\hline
\end{tabular}

Table 2a: cBRP2 Ibio-number calculation and inter-laboratory precision. CZE data derived from Table 3b of Behr-Gross et al. 2004 [13] - Isoform distribution (in \%) of cBRP2, using isoform bioactivities published by Amgen [18].

\begin{tabular}{|c|c|c|c|c|c|c|c|c|c|c|c|c|c|c|c|c|}
\hline \multirow{2}{*}{$\begin{array}{l}\text { Peak } \\
\text { No. }\end{array}$} & \multirow{2}{*}{ 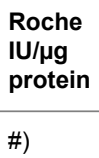 } & \multirow[b]{2}{*}{ Factor } & \multicolumn{2}{|c|}{ Lab 2} & \multicolumn{2}{|c|}{ Lab 3} & \multicolumn{2}{|c|}{ Lab 8} & \multicolumn{2}{|c|}{ Lab 9} & \multicolumn{2}{|c|}{ Lab 10} & \multicolumn{2}{|c|}{ Lab 11} & \multicolumn{2}{|c|}{ Lab 12} \\
\hline & & & pn & in & $\mathrm{pn}$ & in & pn & in & pn & in & $\mathrm{pn}$ & in & $\mathrm{pn}$ & in & pn & in \\
\hline 1 & 19 & 0.19 & & & & & 0.3 & 0.1 & 0.5 & 0.1 & 0.4 & 0.1 & 0.3 & 0.1 & 0.2 & 0.0 \\
\hline 2 & 40 & 0.40 & 1.0 & 0.4 & 1.0 & 0.4 & 1.6 & 0.6 & 0.9 & 0.4 & 1.3 & 0.5 & 1.5 & 0.6 & 1.0 & 0.4 \\
\hline 3 & 75 & 0.75 & 4.5 & 3.4 & 4.9 & 3.7 & 5.1 & 3.8 & 3.8 & 2.9 & 4.6 & 3.5 & 5.2 & 3.9 & 5.3 & 4.0 \\
\hline 4 & 150 & 1.50 & 16.8 & 25.2 & 16.8 & 25.2 & 16.2 & 24.3 & 17.3 & 26.0 & 15.4 & 23.1 & 19.0 & 28.5 & 17.3 & 26.0 \\
\hline 5 & 200 & 2.00 & 27.1 & 54.2 & 27.2 & 54.4 & 26.3 & 52.6 & 27.8 & 55.6 & 26.8 & 53.6 & 28.7 & 57.4 & 26.9 & 53.8 \\
\hline 6 & 280 & 2.80 & 30.4 & 85.1 & 29.7 & 83.2 & 30.0 & 84.0 & 29.4 & 82.3 & 30.4 & 85.1 & 30.0 & 84.0 & 29.6 & 82.9 \\
\hline 7 & 400 & 4.00 & 18.6 & 74.4 & 18.3 & 73.2 & 18.6 & 74.4 & 18.6 & 74.4 & 19.2 & 76.8 & 15.2 & 60.8 & 18.1 & 72.4 \\
\hline 8 & 205.8 & 2.06 & 1.7 & 3.5 & 2.1 & 4.3 & 1.8 & 3.7 & 1.8 & 3.7 & 1.9 & 3.9 & 0.1 & 0.2 & 1.7 & 3.5 \\
\hline \multicolumn{3}{|c|}{ Ibio_R_primary = } & \multicolumn{2}{|c|}{246.2} & \multicolumn{2}{|c|}{244.4} & \multicolumn{2}{|c|}{243.5} & \multicolumn{2}{|c|}{245.3} & \multicolumn{2}{|c|}{246.6} & \multicolumn{2}{|c|}{235.5} & \multicolumn{2}{|l|}{242.9} \\
\hline \multicolumn{3}{|c|}{ |bio_R_final = } & \multicolumn{2}{|c|}{147.7} & \multicolumn{2}{|c|}{146.6} & \multicolumn{2}{|c|}{146.1} & \multicolumn{2}{|c|}{147.2} & \multicolumn{2}{|c|}{147.9} & \multicolumn{2}{|c|}{141.3} & \multicolumn{2}{|c|}{145.8} \\
\hline \multicolumn{5}{|c|}{ Mean Ibio_R $=146.1 \pm 2.3$} & \multicolumn{4}{|c|}{$(n=7)$} & & & & & & & & \\
\hline \multicolumn{3}{|c|}{ Mean Ibio_R $=146.9 \pm 0.9$} & \multicolumn{2}{|c|}{$C V=0.6 \%$} & & $=6)$ & & & & & & & & & & \\
\hline
\end{tabular}

Table 2b: Using isoform bioactivities published by Roche [19]. \#) Specific activity of isoform peak no. 8 as published by Amgen [18] as the specific activity of this isoform of Roche [19] was not available. Note: Lab 11 proved to be an outlier according to Grubbs ( $\alpha=0.05)$ and according to Dixon $(\alpha=0.02)$ and was therefore disregarded.

\begin{tabular}{|l|l|l|l|l|l|l|l|l|}
\hline & Lab no. & $\mathbf{2}$ & $\mathbf{3}$ & $\mathbf{8}$ & $\mathbf{9}$ & $\mathbf{1 0}$ & $\mathbf{1 2}$ & cp. Table 2a \\
\hline CBRP2 & $\mathrm{A}$ & 139.9 & 139.2 & 138.2 & 139.8 & 139.5 & 138.6 & \\
\hline & $\mathrm{R}$ & 147.7 & 146.6 & 146.1 & 147.2 & 147.9 & 145.8 & cp. Table 2b \\
\hline & Mean & 143.8 & 142.9 & 142.2 & 143.5 & 143.7 & 142.2 & \\
\hline
\end{tabular}

Table 2c: Mean of means. Note: Lab 11 (not shown) proved to be an outlier according to Grubbs $(\alpha=0.05)$ and according to Dixon ( $\alpha=0.02)$ and was therefore disregarded. 
Citation: Hermentin P (2017) Ibio-Number Assay and Erythropoietin Bioactivity: Comparison of the Calculated and the Stated Potencies of the Biological Reference Preparations of Erythropoietin. Pharm Anal Acta 8: 542. doi:10.4172/2153-2435.1000542

Page 5 of 12

\begin{tabular}{|c|c|c|c|c|c|c|c|c|c|c|c|c|c|c|c|c|c|c|c|c|c|c|}
\hline \multirow[t]{2}{*}{$\begin{array}{l}\text { Peak } \\
\text { No. }\end{array}$} & \multirow{2}{*}{$\begin{array}{l}\text { Amgen } \\
\text { IU/pg } \\
\text { poly- } \\
\text { peptide }\end{array}$} & \multirow[b]{2}{*}{$\begin{array}{l}\text { Fact } \\
\text { or }\end{array}$} & \multicolumn{2}{|c|}{ Lab 1} & \multicolumn{2}{|c|}{ Lab 2} & \multicolumn{2}{|c|}{ Lab 3} & \multicolumn{2}{|c|}{ Lab 4} & \multicolumn{2}{|c|}{ Lab 6} & \multicolumn{2}{|l|}{ Lab 7} & \multicolumn{2}{|c|}{ Lab 9} & \multicolumn{2}{|c|}{ Lab 13} & \multicolumn{2}{|c|}{ Lab 15} & \multicolumn{2}{|c|}{ Lab 16} \\
\hline & & & pn & in & pn & in & pn & in & pn & in & pn & in & pn & in & pn & in & pn & in & pn & in & pn & in \\
\hline 1 & 50.3 & 0.50 & 0.1 & 0.1 & 0.0 & 0.0 & 0.5 & 0.3 & 0.0 & 0.0 & 0.3 & 0.2 & 0.0 & 0.0 & 0.1 & 0.1 & 0.0 & 0.0 & 0.2 & 0.1 & 0.1 & 0.1 \\
\hline 2 & 70.6 & 0.71 & 1.1 & 0.8 & 0.4 & 0.3 & 1.5 & 1.1 & 1.0 & 0.7 & 1.3 & 0.9 & 1.1 & 0.8 & 0.7 & 0.5 & 0.6 & 0.4 & 1.1 & 0.8 & 1.0 & 0.7 \\
\hline 3 & 96.6 & 0.97 & 4.8 & 4.6 & 5.8 & 5.6 & 4.9 & 4.7 & 4.2 & 4.1 & 4.9 & 4.7 & 4.5 & 4.3 & 2.7 & 2.6 & 4.3 & 4.2 & 4.8 & 4.6 & 4.6 & 4.4 \\
\hline 4 & 170.3 & 1.70 & 16.7 & 28.4 & 16.8 & 28.6 & 16.9 & 28.8 & 16.1 & 27.4 & 17.4 & 29.6 & 17.5 & 29.8 & 17.4 & 29.6 & 16.6 & 28.3 & 17.0 & 29.0 & 16.9 & 28.8 \\
\hline 5 & 255.8 & 2.56 & 26.8 & 68.6 & 26.6 & 68.0 & 26.4 & 67.5 & 27.5 & 70.3 & 27.3 & 69.8 & 26.9 & 68.8 & 28.8 & 73.7 & 27.5 & 70.3 & 26.4 & 67.5 & 27.5 & 70.3 \\
\hline 6 & 258.4 & 2.58 & 29.8 & 77.0 & 29.7 & 76.7 & 29.6 & 76.5 & 30.2 & 78.0 & 29.5 & 76.2 & 29.2 & 75.5 & 30.0 & 77.5 & 29.8 & 77.0 & 29.7 & 76.7 & 29.7 & 76.7 \\
\hline 7 & 258.7 & 2.59 & 18.9 & 48.9 & 18.8 & 48.6 & 18.4 & 47.6 & 19.4 & 50.2 & 17.9 & 46.3 & 18.8 & 48.6 & 18.5 & 47.9 & 18.9 & 48.9 & 18.6 & 48.1 & 18.1 & 46.8 \\
\hline 8 & 205.8 & 2.06 & 1.8 & 3.7 & 1.9 & 3.9 & 1.8 & 3.7 & 1.6 & 3.3 & 1.5 & 3.1 & 2.0 & 4.1 & 1.8 & 3.7 & 2.3 & 4.7 & 2.0 & 4.1 & 1.8 & 3.7 \\
\hline \multicolumn{3}{|c|}{ Ibio_A_primary = } & \multicolumn{2}{|c|}{232.1} & \multicolumn{2}{|l|}{231.8} & \multicolumn{2}{|l|}{230.1} & \multicolumn{2}{|l|}{234.0} & \multicolumn{2}{|l|}{230.9} & \multicolumn{2}{|l|}{231.9} & \multicolumn{2}{|l|}{235.5} & \multicolumn{2}{|l|}{233.8} & \multicolumn{2}{|l|}{231.0} & \multicolumn{2}{|l|}{231.6} \\
\hline \multicolumn{3}{|c|}{ Ibio_A_final = } & \multicolumn{2}{|c|}{139.2} & \multicolumn{2}{|l|}{139.1} & \multicolumn{2}{|l|}{138.1} & \multicolumn{2}{|l|}{140.4} & \multicolumn{2}{|l|}{138.5} & \multicolumn{2}{|l|}{139.2} & 141.3 & & 140.3 & & 138.6 & & 139.0 & \\
\hline Mea & $1-1$ & +1 & & & & & 0.16 & & & & & & & & & & & & & & & \\
\hline
\end{tabular}

Table 3a: BRP2 Ibio-number calculation and inter-laboratory precision. CZE data derived from Table 3c of Behr-Gross et al. 2007 [14] - Isoform distribution (in \%) of BRP2 uncorrected for migration time, using isoform bioactivities published by Amgen [18].

\begin{tabular}{|c|c|c|c|c|c|c|c|c|c|c|c|c|c|c|c|c|c|c|c|c|c|c|}
\hline \multirow[t]{2}{*}{$\begin{array}{l}\text { Peak } \\
\text { No. }\end{array}$} & \multirow{2}{*}{$\begin{array}{l}\begin{array}{l}\text { Roche } \\
\text { IU/pg } \\
\text { protein }\end{array} \\
\text { \#) }\end{array}$} & \multirow[b]{2}{*}{$\begin{array}{l}\text { Fact } \\
\text { or }\end{array}$} & \multicolumn{2}{|c|}{ Lab 1} & \multicolumn{2}{|c|}{ Lab 2} & \multicolumn{2}{|c|}{ Lab 3} & \multicolumn{2}{|l|}{ Lab 4} & \multicolumn{2}{|l|}{ Lab 6} & \multicolumn{2}{|c|}{ Lab 7} & \multicolumn{2}{|c|}{ Lab 9} & \multicolumn{2}{|c|}{ Lab 13} & \multicolumn{2}{|c|}{ Lab 15} & \multicolumn{2}{|c|}{ Lab 16} \\
\hline & & & $\mathrm{pn}$ & in & pn & in & pn & in & $\mathrm{pn}$ & in & pn & in & $\mathrm{pn}$ & in & $\mathrm{pn}$ & in & pn & in & $\mathrm{pn}$ & in & pn & in \\
\hline 1 & 19 & 0.19 & 0.1 & 0.0 & 0.0 & 0.0 & 0.5 & 0.1 & 0.0 & 0.0 & 0.3 & 0.1 & 0.0 & 0.0 & 0.1 & 0.0 & 0.0 & 0.0 & 0.2 & 0.0 & 0.1 & 0.0 \\
\hline 2 & 40 & 0.40 & 1.1 & 0.4 & 0.4 & 0.2 & 1.5 & 0.6 & 1.0 & 0.4 & 1.3 & 0.5 & 1.1 & 0.4 & 0.7 & 0.3 & 0.6 & 0.2 & 1.1 & 0.4 & 1.0 & 0.4 \\
\hline 3 & 75 & 0.75 & 4.8 & 3.6 & 5.8 & 4.4 & 4.9 & 3.7 & 4.2 & 3.2 & 4.9 & 3.7 & 4.5 & 3.4 & 2.7 & 2.0 & 4.3 & 3.2 & 4.8 & 3.6 & 4.6 & 3.5 \\
\hline 4 & 150 & 1.50 & 16.7 & 25.1 & 16.8 & 25.2 & 16.9 & 25.4 & 16.1 & 24.2 & 17.4 & 26.1 & 17.5 & 26.3 & 17.4 & 26.1 & 16.6 & 24.9 & 17.0 & 25.5 & 16.9 & 25.4 \\
\hline 5 & 200 & 2.00 & 26.8 & 53.6 & 26.6 & 53.2 & 26.4 & 52.8 & 27.5 & 55.0 & 27.3 & 54.6 & 26.9 & 53.8 & 28.8 & 57.6 & 27.5 & 55.0 & 26.4 & 52.8 & 27.5 & 55.0 \\
\hline 6 & 280 & 2.80 & 29.8 & 83.4 & 29.7 & 83.2 & 29.6 & 82.9 & 30.2 & 84.6 & 29.5 & 82.6 & 29.2 & 81.8 & 30.0 & 84.0 & 29.8 & 83.4 & 29.7 & 83.2 & 29.7 & 83.2 \\
\hline 7 & 400 & 4.00 & 18.9 & 75.6 & 18.8 & 75.2 & 18.4 & 73.6 & 19.4 & 77.6 & 17.9 & 71.6 & 18.8 & 75.2 & 18.5 & 74.0 & 18.9 & 75.6 & 18.6 & 74.4 & 18.1 & 72.4 \\
\hline 8 & 205.8 & 2.06 & 1.8 & 3.7 & 1.9 & 3.9 & 1.8 & 3.7 & 1.6 & 3.3 & 1.5 & 3.1 & 2.0 & 4.1 & 1.8 & 3.7 & 2.3 & 4.7 & 2.0 & 4.1 & 1.8 & 3.7 \\
\hline \multicolumn{3}{|c|}{ Ibio_R_primary = } & \multicolumn{2}{|c|}{245.5} & \multicolumn{2}{|c|}{245.2} & \multicolumn{2}{|l|}{242.7} & \multicolumn{2}{|l|}{248.2} & \multicolumn{2}{|l|}{242.2} & \multicolumn{2}{|c|}{244.9} & \multicolumn{2}{|c|}{247.7} & \multicolumn{2}{|l|}{247.1} & \multicolumn{2}{|l|}{244.1} & \multicolumn{2}{|c|}{243.5} \\
\hline \multicolumn{3}{|c|}{ Ibio_R_final = } & \multicolumn{2}{|c|}{147.3} & \multicolumn{2}{|c|}{147.1} & \multicolumn{2}{|l|}{145.6} & \multicolumn{2}{|c|}{148.9} & \multicolumn{2}{|l|}{145.3} & \multicolumn{2}{|c|}{147.0} & 148.6 & & 148.3 & & 146.4 & & 146.1 & \\
\hline Mear & $R=$ & \pm 1 & & & 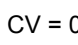 & & & & -10 & & & & & & & & & & & & & \\
\hline
\end{tabular}

Table 3b: Using isoform bioactivities published by Roche [19]. \#) Specific activity of isoform peak no. 8 as published by Amgen [18] as the specific activity of this isoform of Roche [19] was not available. 
Citation: Hermentin P (2017) Ibio-Number Assay and Erythropoietin Bioactivity: Comparison of the Calculated and the Stated Potencies of the Biological Reference Preparations of Erythropoietin. Pharm Anal Acta 8: 542. doi:10.4172/2153-2435.1000542

Page 6 of 12

\begin{tabular}{|c|c|c|c|c|c|c|c|c|c|c|c|c|}
\hline & Lab no. & 1 & 2 & 3 & 4 & 6 & 7 & 9 & 13 & 15 & 16 & \\
\hline \multirow[t]{3}{*}{ BRP2 } & A & 139.2 & 139.1 & 138.1 & 140.4 & 138.5 & 139.2 & 141.3 & 140.3 & 138.6 & 139.0 & Cp. Table 3a \\
\hline & $\mathrm{R}$ & 147.3 & 147.1 & 145.6 & 148.9 & 145.3 & 147.0 & 148.6 & 148.3 & 146.4 & 146.1 & Cp. Table $3 b$ \\
\hline & Mean & 143.3 & 143.1 & 141.9 & 144.7 & 141.9 & 143.1 & 145.0 & 144.3 & 142.5 & 142.5 & \\
\hline
\end{tabular}

Table 3c: Mean of means. A: Ibio-numbers calculated using isoform factors deduced from ref [18], R: Ibio-numbers calculated using isoform factors deduced from ref [19].

\begin{tabular}{|c|c|c|c|c|c|c|c|c|c|c|c|c|}
\hline \multirow[t]{2}{*}{ Peak No. } & \multirow{2}{*}{$\begin{array}{l}\text { Amgen IU/pg } \\
\text { poly-peptide }\end{array}$} & \multirow[b]{2}{*}{ Factor } & \multicolumn{2}{|c|}{ Lab 1} & \multicolumn{2}{|l|}{ Lab 2} & \multicolumn{2}{|c|}{ Lab 3} & \multicolumn{2}{|c|}{ Lab 4} & \multicolumn{2}{|c|}{ Lab 5} \\
\hline & & & pn & in & pn & in & pn & in & pn & in & pn & in \\
\hline 1 & 50.3 & 0.50 & 0.7 & 0.4 & 0.4 & 0.2 & 0.5 & 0.3 & 0.5 & 0.3 & 0.6 & 0.3 \\
\hline 2 & 70.6 & 0.71 & 2.4 & 1.7 & 1.2 & 0.8 & 2.0 & 1.4 & 1.7 & 1.2 & 2.1 & 1.5 \\
\hline 3 & 96.6 & 0.97 & 5.3 & 5.1 & 3.2 & 3.1 & 6.0 & 5.8 & 5.7 & 5.5 & 5.7 & 5.5 \\
\hline 4 & 170.3 & 1.70 & 17.3 & 29.5 & 16.0 & 27.2 & 18.3 & 31.2 & 19.6 & 33.4 & 18.4 & 31.3 \\
\hline 5 & 255.8 & 2.56 & 26.6 & 68.0 & 27.7 & 70.9 & 27.4 & 70.1 & 27.4 & 70.1 & 27.7 & 70.9 \\
\hline 6 & 258.4 & 2.58 & 28.2 & 72.9 & 30.9 & 79.8 & 27.7 & 71.6 & 27.9 & 72.1 & 27.7 & 71.6 \\
\hline 7 & 258.7 & 2.59 & 17.7 & 45.8 & 19.0 & 49.2 & 16.5 & 42.7 & 15.8 & 40.9 & 16.3 & 42.2 \\
\hline 8 & 205.8 & 2.06 & 1.8 & 3.7 & 1.6 & 3.3 & 1.6 & 3.3 & 1.4 & 2.9 & 1.5 & 3.1 \\
\hline \multicolumn{3}{|c|}{ Ibio_A_primary = } & \multicolumn{2}{|c|}{227.0} & \multicolumn{2}{|c|}{234.5} & \multicolumn{2}{|c|}{226.3} & \multicolumn{2}{|c|}{226.3} & \multicolumn{2}{|c|}{226.3} \\
\hline \multicolumn{3}{|c|}{ Ibio_A_final = } & \multicolumn{2}{|c|}{136.2} & \multicolumn{2}{|l|}{140.7} & \multicolumn{2}{|c|}{135.8} & \multicolumn{2}{|c|}{135.8} & \multicolumn{2}{|c|}{135.8} \\
\hline \multicolumn{3}{|c|}{ Mean Ibio_A $=136.9 \pm 2.2$} & $C V=1.6$ & & \multicolumn{8}{|c|}{$(n=5)$} \\
\hline \multicolumn{3}{|c|}{ Mean Ibio_A $=135.9 \pm 0.2$} & $C V=0.2$ & & \multicolumn{4}{|c|}{$(n=4)$} & & & & \\
\hline
\end{tabular}

Table 4a: BRP3 Ibio-number calculation and inter-laboratory precision. CZE data derived from Table 7 of Burns et al. 2015 [15] - Isoform content of BRP3 (in \%) uncorrected, using isoform bioactivities published by Amgen [18].

\begin{tabular}{|c|c|c|c|c|c|c|c|c|c|c|c|c|}
\hline \multirow[t]{2}{*}{ Peak No. } & \multirow{2}{*}{$\begin{array}{l}\text { Roche IU/pg } \\
\text { protein } \\
\#)\end{array}$} & \multirow[b]{2}{*}{ Factor } & \multicolumn{2}{|c|}{ Lab 1} & \multicolumn{2}{|c|}{ Lab 2} & \multicolumn{2}{|c|}{ Lab 3} & \multicolumn{2}{|c|}{ Lab 4} & \multicolumn{2}{|c|}{ Lab 5} \\
\hline & & & pn & in & pn & in & pn & in & pn & in & pn & in \\
\hline 1 & 19 & 0.19 & 0.7 & 0.1 & 0.4 & 0.1 & 0.5 & 0.1 & 0.5 & 0.1 & 0.6 & 0.1 \\
\hline 2 & 40 & 0.40 & 2.4 & 1.0 & 1.2 & 0.5 & 2.0 & 0.8 & 1.7 & 0.7 & 2.1 & 0.8 \\
\hline 3 & 75 & 0.75 & 5.3 & 4.0 & 3.2 & 2.4 & 6.0 & 4.5 & 5.7 & 4.3 & 5.7 & 4.3 \\
\hline 4 & 150 & 1.50 & 17.3 & 26.0 & 16.0 & 24.0 & 18.3 & 27.5 & 19.6 & 29.4 & 18.4 & 27.6 \\
\hline 5 & 200 & 2.00 & 26.6 & 53.2 & 27.7 & 55.4 & 27.4 & 54.8 & 27.4 & 54.8 & 27.7 & 55.4 \\
\hline
\end{tabular}


Citation: Hermentin P (2017) Ibio-Number Assay and Erythropoietin Bioactivity: Comparison of the Calculated and the Stated Potencies of the Biological Reference Preparations of Erythropoietin. Pharm Anal Acta 8: 542. doi:10.4172/2153-2435.1000542

Page 7 of 12

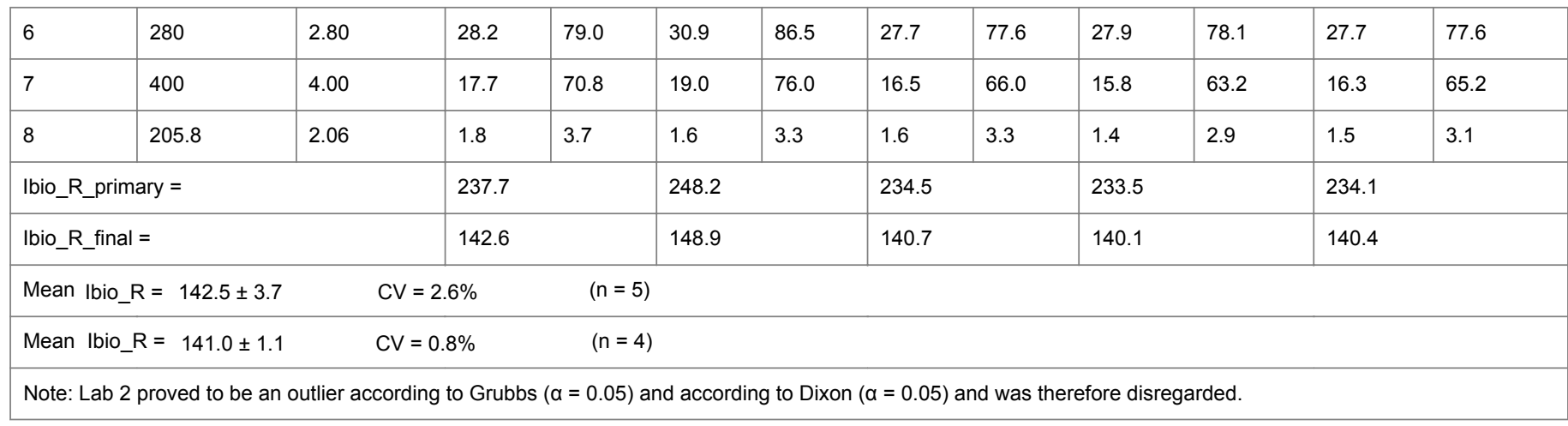

Table 4b: Using isoform bioactivities published by Roche [19]. \#) Specific activity of isoform peak no. 8 as published by Amgen [18] as the specific activity of this isoform of Roche [19] was not available.

\begin{tabular}{|c|c|c|c|c|c|c|}
\hline \multirow{4}{*}{ BRP3 } & Lab no. & 1 & 3 & 4 & 5 & \multirow{2}{*}{ cp. Table 4a } \\
\hline & A & 136.2 & 135.8 & 135.8 & 135.8 & \\
\hline & $\mathrm{R}$ & 142.6 & 140.7 & 140.1 & 140.4 & \multirow{2}{*}{ cp. Table 4b } \\
\hline & Mean & 139.4 & 138.2 & 137.9 & 138.1 & \\
\hline \multicolumn{7}{|c|}{ 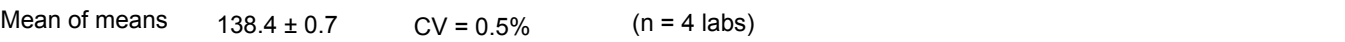 } \\
\hline
\end{tabular}

Table 4c: Mean of means. A: Ibio-numbers calculated using isoform factors deduced from ref [18]. R: Ibio-numbers calculated using isoform factors deduced from ref [19].

\begin{tabular}{|c|c|c|c|c|c|c|c|c|c|c|c|c|}
\hline \multirow[t]{2}{*}{ Peak No. } & \multirow[t]{2}{*}{$\begin{array}{l}\text { Amgen IU/pg } \\
\text { poly-peptide }\end{array}$} & \multirow[b]{2}{*}{ Factor } & \multicolumn{2}{|c|}{ Lab 1} & \multicolumn{2}{|c|}{ Lab 2} & \multicolumn{2}{|c|}{ Lab 3} & \multicolumn{2}{|c|}{ Lab 4} & \multicolumn{2}{|c|}{ Lab 5} \\
\hline & & & pn & in & pn & in & pn & in & pn & in & pn & in \\
\hline 1 & 50.3 & 0.50 & 0.5 & 0.3 & 0.6 & 0.3 & 0.5 & 0.3 & 0.6 & 0.3 & 0.6 & 0.3 \\
\hline 2 & 70.6 & 0.71 & 2.1 & 1.5 & 1.9 & 1.3 & 2.0 & 1.4 & 2.0 & 1.4 & 2.0 & 1.4 \\
\hline 3 & 96.6 & 0.97 & 5.6 & 5.4 & 5.3 & 5.1 & 6.2 & 6.0 & 5.2 & 5.0 & 6.2 & 6.0 \\
\hline 4 & 170.3 & 1.70 & 16.9 & 28.8 & 17.2 & 29.3 & 18.0 & 30.7 & 18.1 & 30.8 & 18.1 & 30.8 \\
\hline 5 & 255.8 & 2.56 & 26.1 & 66.8 & 26.5 & 67.8 & 26.4 & 67.5 & 27.6 & 70.6 & 26.4 & 67.5 \\
\hline 6 & 258.4 & 2.58 & 28.8 & 74.4 & 28.9 & 74.7 & 28.2 & 72.9 & 28.2 & 72.9 & 28.3 & 73.1 \\
\hline 7 & 258.7 & 2.59 & 18.4 & 47.6 & 17.5 & 45.3 & 17.1 & 44.2 & 17.0 & 44.0 & 16.9 & 43.7 \\
\hline 8 & 205.8 & 2.06 & 1.7 & 3.5 & 2.2 & 4.5 & 1.6 & 3.3 & 1.2 & 2.5 & 1.3 & 2.7 \\
\hline \multicolumn{3}{|c|}{ Ibio_primary = } & \multicolumn{2}{|c|}{228.2} & \multicolumn{2}{|c|}{228.3} & \multicolumn{2}{|c|}{226.2} & \multicolumn{2}{|c|}{227.5} & \multicolumn{2}{|c|}{225.6} \\
\hline \multicolumn{3}{|c|}{ Ibio_final = } & \multicolumn{2}{|c|}{136.9} & \multicolumn{2}{|c|}{137.0} & \multicolumn{2}{|c|}{135.7} & \multicolumn{2}{|c|}{136.5} & \multicolumn{2}{|c|}{135.3} \\
\hline \multicolumn{3}{|c|}{ Mean Ibio $=136.3 \pm 0.7$} & $5 \%$ & & & & & & & & & \\
\hline
\end{tabular}

Table 5a: cCRS Ibio-number calculation and inter-laboratory precision. CZE data derived from Table 6 of Burns et al. 2015 [15] - Isoform content of cCRS (in \%) uncorrected, using isoform bioactivities published by Amgen [18]. 
Citation: Hermentin P (2017) Ibio-Number Assay and Erythropoietin Bioactivity: Comparison of the Calculated and the Stated Potencies of the Biological Reference Preparations of Erythropoietin. Pharm Anal Acta 8: 542. doi:10.4172/2153-2435.1000542

Page 8 of 12

\begin{tabular}{|c|c|c|c|c|c|c|c|c|c|c|c|c|}
\hline \multirow[t]{2}{*}{ Peak No. } & \multirow{2}{*}{$\begin{array}{l}\text { Roche IU/pg } \\
\text { protein }\end{array}$} & \multirow[b]{2}{*}{ Factor } & \multicolumn{2}{|l|}{ Lab 1} & \multicolumn{2}{|l|}{ Lab 2} & \multicolumn{2}{|c|}{ Lab 3} & \multicolumn{2}{|l|}{ Lab 4} & \multicolumn{2}{|c|}{ Lab 5} \\
\hline & & & pn & in & $\mathrm{pn}$ & in & pn & in & pn & in & pn & in \\
\hline 1 & 19 & 0.19 & 0.5 & 0.1 & 0.6 & 0.1 & 0.5 & 0.1 & 0.6 & 0.1 & 0.6 & 0.1 \\
\hline 2 & 40 & 0.40 & 2.1 & 0.8 & 1.9 & 0.8 & 2.0 & 0.8 & 2.0 & 0.8 & 2.0 & 0.8 \\
\hline 3 & 75 & 0.75 & 5.6 & 4.2 & 5.3 & 4.0 & 6.2 & 4.7 & 5.2 & 3.9 & 6.2 & 4.7 \\
\hline 4 & 150 & 1.50 & 16.9 & 25.4 & 17.2 & 25.8 & 18.0 & 27.0 & 18.1 & 27.2 & 18.1 & 27.2 \\
\hline 5 & 200 & 2.00 & 26.1 & 52.2 & 26.5 & 53.0 & 26.4 & 52.8 & 27.6 & 55.2 & 26.4 & 52.8 \\
\hline 6 & 280 & 2.80 & 28.8 & 80.6 & 28.9 & 80.9 & 28.2 & 79.0 & 28.2 & 79.0 & 28.3 & 79.2 \\
\hline 7 & 400 & 4.00 & 18.4 & 73.6 & 17.5 & 70.0 & 17.1 & 68.4 & 17.0 & 68.0 & 16.9 & 67.6 \\
\hline 8 & 205.8 & 2.06 & 1.7 & 3.5 & 2.2 & 4.5 & 1.6 & 3.3 & 1.2 & 2.5 & 1.3 & 2.7 \\
\hline \multicolumn{3}{|c|}{ Ibio_primary = } & \multicolumn{2}{|l|}{240.4} & \multicolumn{2}{|l|}{239.1} & \multicolumn{2}{|c|}{236.0} & \multicolumn{2}{|l|}{236.6} & \multicolumn{2}{|c|}{235.0} \\
\hline \multicolumn{3}{|c|}{ Ibio_final = } & \multicolumn{2}{|l|}{144.3} & \multicolumn{2}{|l|}{143.5} & \multicolumn{2}{|c|}{141.6} & \multicolumn{2}{|l|}{142.0} & \multicolumn{2}{|c|}{141.0} \\
\hline
\end{tabular}

Table 5b: Using isoform bioactivities published by Roche [19]. \#) Specific activity of isoform peak no. 8 as published by Amgen [18] as the specific activity of this isoform of Roche [19] was not available.

\begin{tabular}{|c|c|c|c|c|c|c|c|}
\hline \multirow{4}{*}{ cCRS } & Lab no. & 1 & 2 & 3 & 4 & 5 & \multirow{2}{*}{ cp. Table 5a } \\
\hline & A & 136.9 & 137.0 & 135.7 & 136.5 & 135.3 & \\
\hline & $\mathrm{R}$ & 144.3 & 143.5 & 141.6 & 142.0 & 141.0 & \multirow{2}{*}{ cp. Table $5 b$} \\
\hline & Mean & 140.6 & 140.2 & 138.7 & 139.2 & 138.2 & \\
\hline \multicolumn{8}{|c|}{ Mean of means } \\
\hline
\end{tabular}

Table 5c: Mean of means. A: Ibio-numbers calculated using isoform factors deduced from ref [18], R: Ibio-numbers calculated using isoform factors deduced from ref [19].

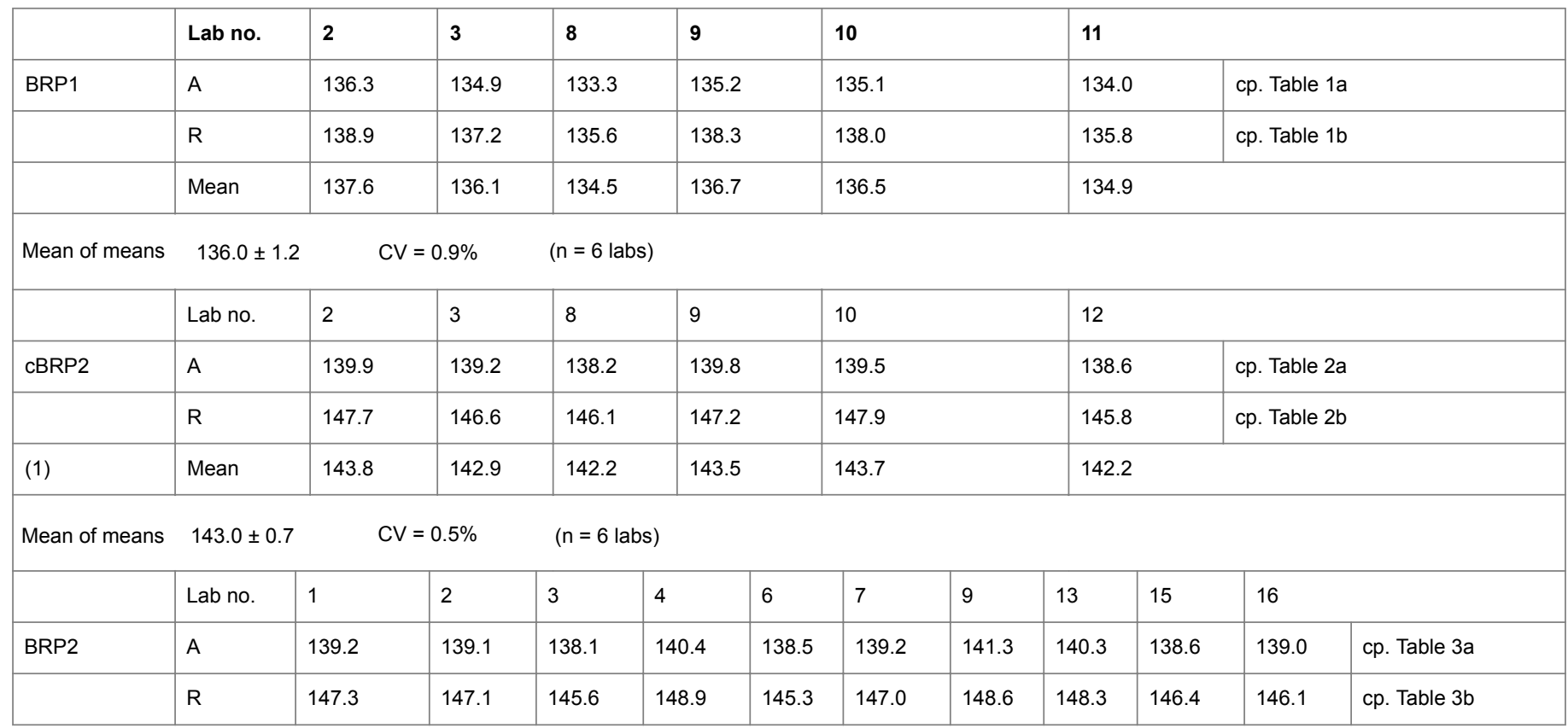


Citation: Hermentin P (2017) Ibio-Number Assay and Erythropoietin Bioactivity: Comparison of the Calculated and the Stated Potencies of the Biological Reference Preparations of Erythropoietin. Pharm Anal Acta 8: 542. doi:10.4172/2153-2435.1000542

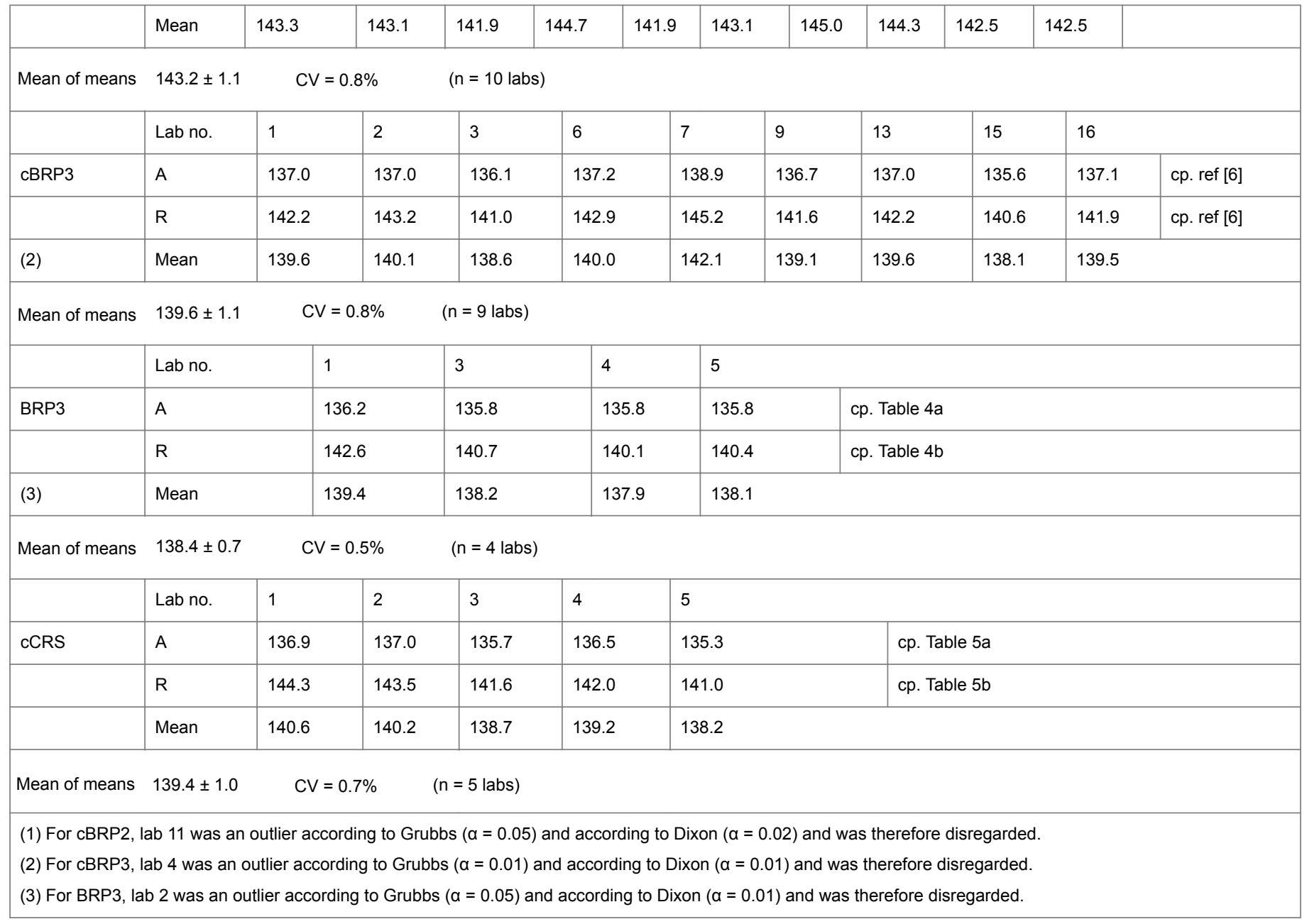

Table 6: Ibio-numbers and inter-laboratory precision (Summary Table). A: Ibio-numbers calculated using isoform factors deduced from ref [18], R: Ibio-numbers calculated using isoform factors deduced from ref [19].

\begin{tabular}{|c|c|c|c|c|c|c|}
\hline \multicolumn{2}{|c|}{ Data from } & \multirow{2}{*}{ 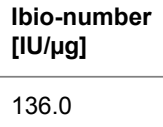 } & \multirow{2}{*}{ 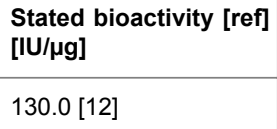 } & \multirow{2}{*}{$\begin{array}{l}\begin{array}{l}\text { Accuracy against stated } \\
\text { bioactivity [\%] }\end{array} \\
104.7\end{array}$} & \multirow{2}{*}{$\begin{array}{l}\begin{array}{l}\text { Difference to stated } \\
\text { bioactivity [\%] }\end{array} \\
+4.7\end{array}$} & \multirow{3}{*}{$\begin{array}{l}\text { Remarks } \\
\begin{array}{l}6 \text { labs, study } 2004 \\
{[13]}\end{array}\end{array}$} \\
\hline BRP1 & Table 1 & & & & & \\
\hline cBRP2 & Table 2 & 143.0 & $130.0[13]$ & 110.0 & +10.0 & \\
\hline BRP2 & Table 3 & 143.2 & $130.0[13]$ & 110.2 & +10.2 & \multirow{2}{*}{$\begin{array}{l}10 \text { labs, study } 2007 \\
{[14]}\end{array}$} \\
\hline cBRP3 & ref [6] & 139.6 & $141.1[14]$ & 98.9 & -1.1 & \\
\hline BRP3 & Table 4 & 138.4 & $141.1[14]$ & 98.1 & -1.9 & \multirow{2}{*}{$\begin{array}{l}5 \text { labs, study } 2015 \\
\text { [15] }\end{array}$} \\
\hline cCRS & Table 5 & 139.4 & 141.1 \#) & 98.8 & -1.2 & \\
\hline
\end{tabular}

Table 7: Ibio-number accuracy determination of sample versus stated bioactivity (Summary Table). 


\section{Results}

A reference electropherogram is shown in Figure 1.

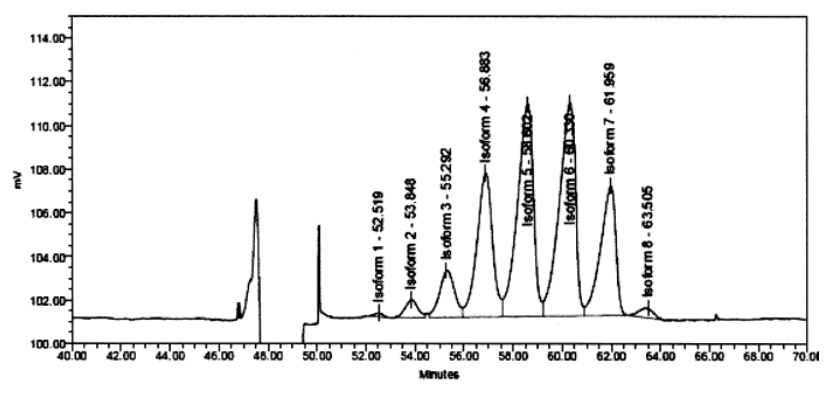

Figure 1: CZE electropherogram of EPO cBRP3, taken from the 2007 study [14] - with permission by EDQM.

\section{Inter-laboratory precision}

Ibio-number calculation for BRP1 from the CZE data published in the 2004 study [13] provided Ibio_BRP1 $=136.0 \mathrm{IU} / \mu \mathrm{g} \pm 1.2 \mathrm{IU} / \mu \mathrm{g}$, corresponding with an inter-laboratory precision of $\mathrm{CV}=0.9 \%(\mathrm{n}=6$ labs) (Table 1).

Ibio-number calculation for CBRP2 from the CZE data published in the 2004 study [13] provided Ibio_cBRP2 $=143.0 \mathrm{IU} / \mu \mathrm{g} \pm 0.7 \mathrm{IU} / \mu \mathrm{g}$, corresponding with an inter-laboratory precision of $\mathrm{CV}=0.5 \%(\mathrm{n}=6$ labs) (Table 2).

Ibio-number calculation for BRP2 from the CZE data published in the 2007 study [14] provided Ibio_BRP2 $=143.2 \mathrm{IU} / \mu \mathrm{g} \pm 1.1 \mathrm{IU} / \mu \mathrm{g}$, corresponding with an inter-laboratory precision of $\mathrm{CV}=0.8 \%(\mathrm{n}=10$ labs) (Table 3), confirming the data of the previous study [13].

Ibio-number calculation for $\mathrm{CBRP} 3$ from the CZE data published in the 2007 study [14] provided Ibio_cBRP3 $=139.6 \mathrm{IU} / \mu \mathrm{g} \pm 1.1 \mathrm{IU} / \mu \mathrm{g}$, corresponding with an inter-laboratory precision of $\mathrm{CV}=0.8 \% ; \mathrm{n}=9$ labs) (for the corresponding Ibio-number calculation see ref [6]).

Ibio-number calculation for BRP3 from the CZE data published in the 2015 study [15] provided Ibio_BRP3 $=138.4 \mathrm{IU} / \mu \mathrm{g} \pm 0.7 \mathrm{IU} / \mu \mathrm{g}$, corresponding with an inter-laboratory precision of $\mathrm{CV}=0.5 \% ; \mathrm{n}=4$ labs) (Table 4), confirming the data of the previous study [14].

Ibio-number calculation for cCRS from the CZE data published in the 2015 study [15] provided Ibio_cCRS $=139.4 \mathrm{IU} / \mu \mathrm{g} \pm 1.0 \mathrm{IU} / \mu \mathrm{g}$, corresponding with an inter-laboratory precision of $\mathrm{CV}=0.7 \%(\mathrm{n}=5$ labs) (Table 5).

In summary, the CZE data of the three collaborative studies [13-15] revealed for the Ibio-number assay an inter-laboratory precision of $\mathrm{CV}$ $<1.0 \%$ each, ranging from $\mathrm{CV}=0.5 \%$ (cBRP2, $\mathrm{BRP} 3$ ) to $\mathrm{CV}=0.9 \%$ (BRP1) (Table 6).

\section{Accuracy}

The bioactivities calculated via the Ibio-number assay were compared with the stated potencies of the BRPs, which were regarded as the "true" potency values $(=100 \%$, each), as summarized in Table 7 .

The bioactivity calculated for BRP1 from the CZE data of the 2004 study [13] (Ibio_BRP1 = $136.0 \mathrm{IU} / \mu \mathrm{g}$ ) differed from the stated bioactivity of BRP1 $(130.0 \mathrm{IU} / \mu \mathrm{g})$ by $+4.7 \%$ (accuracy $=104.7 \%)$.
The bioactivity calculated for CBRP2 from the CZE data of the 2004 study [13] (Ibio_cBRP2 $=143.0 \mathrm{IU} / \mu \mathrm{g}$ ) differed from the stated bioactivity of BRP2 $(130.0 \mathrm{IU} / \mu \mathrm{g})$ by $+10.0 \%$ (accuracy $=110.0 \%)$.

The bioactivity calculated for BRP2 from the CZE data of the 2007 study [14] (Ibio_BRP2 $=143.2 \mathrm{IU} / \mu \mathrm{g}$ ) differed from the stated bioactivity of BRP2 (130.0 IU/ $/ \mu$ g) by $+10.2 \%$ (accuracy $=110.2 \%)$.

The bioactivity calculated for CBRP3 from the CZE data of the 2007 study [14] (Ibio_cBRP3 $=139.6 \mathrm{IU} / \mu \mathrm{g}$ ) matched the stated bioactivity of BRP3 $(141.1 \mathrm{IU} / \mu \mathrm{g})$ with an accuracy of $98.9 \%$ (difference $=-1.1 \%$ ) [6].

The bioactivity calculated for BRP3 from the CZE data of the 2015 study [15] (Ibio_BRP3 $=138.4 \mathrm{IU} / \mu \mathrm{g}$ ) matched the stated bioactivity of BRP3 $(141.1 \mathrm{IU} / \mu \mathrm{g})$ with an accuracy of $98.1 \%$ (difference $=-1.9 \%$ ).

The bioactivity calculated for cCRS from the CZE data of the 2015 study [15] (Ibio_cCRS = 139.4 IU/ $\mu \mathrm{g}$ ) matched the stated bioactivity of BRP3 $(141.1 \mathrm{IU} / \mu \mathrm{g}$ ) with an accuracy of $98.8 \%$ (difference $=-1.2 \%$ ).

\section{Discussion}

The data summarized herein may be regarded as a retrospective application of the Ibio-number assay to CZE data of three collaborative studies [13-15], dealing with EPO BRPs, with respect to "interlaboratory precision" (same material, different labs, different studies) and "accuracy" (Ibio-number versus stated bioactivity set 100\%).

\section{Inter-laboratory precision}

The high inter-laboratory precision of the Ibio-number assay has already been shown elsewhere for CBRP3 on the basis of the CZE data of the 2007 collaborative study [14] which provided CV $=0.8 \%$ ( $n=9$ labs) [6]. The inter-laboratory precision calculated from the CZE data of the 2004 [13] and the 2015 [15] collaborative studies were likewise high, resulting in CV $<1.0 \%$ per study (Table 6 ). This precise set of data primarily relies on the precision and accuracy of CZE. But exactly for that reason, this data simultaneously reflects the bioactivity of the EPO samples in CZE in a likewise precise manner [6]. Thus, CZE of EPO samples provides a means for EPO bioactivity determination of previously unmet precision. The question was whether these precisely determined potency values are likewise accurate, which is discussed in the next section.

\section{Accuracy}

A separate retrospective analysis by the author of the CZE data of the various collaborative studies [13-15] via the I-number assay [10] has provided evidence that the bioactivities of EPO BRP1 and EPO BRP2 have been stated $\sim 5 \%$ and $\sim 10 \%$ too low, respectively [11]. And similar results have been obtained in the current study, relating the Ibio-numbers calculated for the (c)BRPs to the stated bioactivities of the corresponding BRPs.

As can be seen from summary Table 7, the potency calculated via the Ibio-number assay for EPO BRP1 (from the CZE data of the 2004 study [13]) did not fit to the stated potency of EPO BRP1 (difference = $+4.7 \%)$.

Likewise, the potency calculated via the Ibio-number assay for cBRP2 (from the CZE data of the 2004 study [13]) did not fit to the stated potency of EPO BRP2 (difference $=+10.0 \%$ ). 
Likewise, the potency calculated via the Ibio-number assay for BRP2 (from the CZE data of the 2007 study [14]) did not fit to the stated potency of EPO BRP2 (difference $=+10.2 \%$ ).

In contrast, the potency calculated via the Ibio-number assay for cBRP3 (from the CZE data of the 2007 study [14]) fitted well with the stated bioactivity of EPO BRP3 (difference $=-1.1 \%$ ).

Likewise, the potency calculated via the Ibio-number assay for BRP3 (from the CZE data of the 2015 study [15]) matched the stated bioactivity of EPO BRP3 (difference $=-1.9 \%$ ).

And likewise, the potency calculated via the Ibio-number assay for CCRS (from the CZE data of the 2015 study [15]) matched the stated bioactivity of EPO BRP3 (difference $=-1.2 \%$ ).

Why was there such a clear fitting for calculated (c) BRP3 versus stated BRP3 and calculated cCRS versus stated BRP3 and such a clear mismatch for calculated BRP1 versus stated BRP1 as well as calculated (c)BRP2 versus stated BRP2?

An explanation of these mismatches for EPO BRP1 and EPO BRP2 has been given by the author on the basis of the I-number assay elsewhere [11], and the same explanation applies to the Ibio-number assay of the current study. In brief, the 2004 study [13] has neglected that the differences in the isoform composition of EPO BRP1 and CBRP2, as revealed in CZE, necessarily must have changed the bioactivity of the product when changing from BRP1 to BRP2. Yet, the potency of BRP2 has been assigned to $32,500 \mathrm{IU} /$ vial, i.e. identical to BRP1. This identical potency assignment did not consider the fact that the percent shares of isoforms 3 and 7 of BRP1 and CBRP2 had changed $($ IF3BRP1 $=6.14 \%$, IF3cBRP2 $=4.68 \%$; IF7BRP1 $=14.51 \%$, IF7cBRP2 $=18.09 \%$; $\mathrm{cp}$. Table $3 \mathrm{a}$ and Table $3 \mathrm{~b}$ of ref [13]), resulting in different Ibio-numbers (Ibio_BRP1 $=136.0 \mathrm{IU} / \mu \mathrm{g}$, Table 1; Ibio_cBRP2 $=143.0 \mathrm{IU} / \mu \mathrm{g}$, Table 2 ). Hence, the Ph. Eur. specification of isoforms 3 and 7 had to be changed (Ph. Eur. 2002 [23]: IF3 = 5-20\%, IF7 = 0-20\%; Ph. Eur. 2008 [24]: IF3 = 1-20\%; IF7 = 5-25\%). The lower content $(\mathrm{pn})$ of isoform 3 concomitant with the higher content (pn) of isoform 7 in BRP2 is clearly reflected in the Ibionumbers which increased from Ibio_BRP1 $=136.0 \mathrm{IU} / \mu \mathrm{g}$ to Ibio_cBRP2 $=143.0 \mathrm{IU} / \mu \mathrm{g}$ (an increase of $~ 5.0 \%$ ), however was not expressed in the assigned bioactivities of 32,500 IU/vial, each.

Thus, erythropoietin medicinal products that have been calibrated against erythropoietin reference preparation batch 1 or batch 2 have been subject to the same error which was, however, within the error of the mouse bioassay and therefore not crucial. The validity of the potencies achieved upon calibration against EPO BRP1 or EPO BRP2 was also ensured by the broad range allowed by $\mathrm{Ph}$. Eur. for potency determination ("The estimated potency is not less than 80 per cent and not more than 125 per cent of the stated potency. The confidence limits of the estimated potency $(\mathrm{P}=0.95)$ are not less than 64 per cent and not more than 156 per cent of the stated potency" $[7,23,24])$.

No CZE data were provided in the 2015 study dedicated to establish EPO BRP batch 4 [16], as this batch was limited to serve as a reference for the bioassay in mice and not intended as a reference for physicochemical assays. EPO BRP batch 4 and EPO cCRS were prepared from the same material. Hence, their bioactivities should be identical (i.e., 139.4 IU/ $\mu \mathrm{g}$ ), as calculated for Ibio_cCRS (Table 5).

EPO BRP batch 4 has an assigned potency of $13000 \mathrm{IU} / \mathrm{vial}$ and contains around $100 \mu \mathrm{g}$ of EPO per vial [16], equivalent to a potency of $130.0 \mathrm{IU} / \mu \mathrm{g}$, which in fact differs from the calculated potency (Ibio_cCRS $=139.4 \mathrm{IU} / \mu \mathrm{g}$ ) by $\sim 7 \%$, which is further addressed below.
The WHO 3rd IS for erythropoietin, recombinant, for bioassay $(11 / 170)$ is not intended as a reference standard for CZE either; therefore, again no CZE data have been published for this material. Noteworthy, "the third IS for erythropoietin is no longer a mixture of alpha and beta erythropoietin but contains only epoetin alpha" [25]. Hence, Ibio-number calculation is solely based on the isoform bioactivities of epoetin alfa, which is marketed in the USA by Amgen (for general anemia) and by Johnson and Johnson (for anemias of cancer) [25]. In fact, an epoetin alfa material from Johnson \& Johnson Ortho Biotec was retrospectively used by the author to calculate the Ibio-number that could reflect the potency of the 3rd IS, namely Centocor's epoetin alfa secondary standard, the CZE data of which have been made available to the public [22]. However, it is unclear (at least to the author) whether the EPO material used to prepare the 3rd IS was in fact from Johnson\& Johnson. Nevertheless, the potency of this epoetin alfa secondary standard from Centocor (respectively Johnson \& Johnson) was calculated by the author via the Ibio-number assay, resulting in Ibio_ $\alpha=142.3 \mathrm{IU} / \mu \mathrm{g}$ [6]. This potency matched the declared potency of the 3rd IS (set 100\%) with an accuracy of $94.9 \%$ (difference $=-5.1 \%)$

The reason for this difference may be due to the chosen manufacturer or due to different batches (of the same manufacturer) or due to the lack of precision of the mouse bioassay or each of these (and the same arguments hold true for EPO BRP4 batch 4 , see above). In fact, the mouse bioassay is highly inaccurate $(\mathrm{CV} \approx 25 \%[1,2], \approx$ $20 \%[3,4]$; uncertainty $15-30 \%$ [5] as stated by Zimmermann et al. [3]), and lack of batch-to-batch consistency of biologics or biosimilars will remain an issue for each manufacturer. For example, the bioactivity determined in normocythaemic mice of 17 epoetin beta 'validation batches' from Roche, which were of the medium range of Roche's well established NeoRecormon production, covered a range of 187.0-241.4

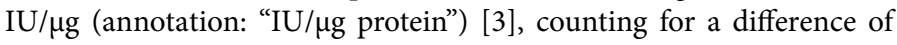
these two values of $\sim 25 \%$.

This indicates the major problem in assigning what may be regarded as the "true" potency value of erythropoietin: It will hardly be possible to compare the results of the highly precise and accurate Ibio-number assay with potencies measured via the most variable mouse bioassay in a reliable way - unless the bioassay data are gathered in an elaborate collaborative study - as the mouse bioassay "may lead to considerable ranges in activity for both biosimilar and reference product" [26]. Hence, the physicochemical data of EPO potency determination presented herein my support the recently diagnosed "paradigm shift in the European Union", foreseeing "biosimilars entering the clinic without animal studies" [26].

In this regard, it is interesting to know - and this is therefore repeated here - that "in the EU, a new Directive on the protection of animals used for scientific purposes was issued in 2010, which updates and replaces the 1986 Directive 86/609/EEC. The aim of the new Directive is to strengthen legislation, and improve the welfare of those animals still needed to be used, as well as to firmly anchor the principle of the "Three Rs," to Replace, Reduce and Refine the use of animals, in EU legislation. Directive 2010/63/EU has taken full effect from 1 January 2013. According to this Directive, the use of animals for scientific or educational purposes should only be considered where a non-animal alternative is unavailable (preamble 12) and Member States shall ensure that, wherever possible, a scientifically satisfactory method or testing strategy, not entailing the use of live animals, is used instead (Article 4.1)" [26]. 
Perhaps the Ibio-number assay for EPO medicinal products may, like the I-number assay [11,27], turn out to be such an alternative which, on the long term, could save thousands of mice and a lot of money, as well.

Noteworthy, the bioactivities of the EPO samples retrospectively calculated by the author via the Ibio-number assay herein and elsewhere [6] and the I-number assay $[11,27]$ were very comparable with differences between the two assays of $<2.0 \%$, each time, and a mean difference of $1.2 \%$. This closeness of the results is, however, not surprising as both assays are based on the same CZE data.

This quasi-identity of the results of the I-number and the Ibionumber assay shows that it is not necessary to choose the Ibio-number assay for accurate potency determination and to know the bioactivity of the individual EPO isoforms respectively the multiplication factors (cp. Tables 1-5), the determination of which is very laborious, time consuming and costly and needs sacrifice of hundreds of mice. The same results, with the same precision and accuracy, can be achieved using the "simple" I-number assay [11,27].

The advantage of the I-number assay is that this assay can be used without knowing the bioactivities of the individual EPO isoforms, which makes this assay readily applicable for any laboratory and will most likely render it first choice at least during product development and scale-up production. The advantage of the Ibio-number assay is that - once the bioactivities of the EPO isoforms (respectively the multiplication factors) are known - this assay allows to directly calculate the bioactivity of the EPO samples, whereas the I-number assay requires measurement against an EPO reference standard of known bioactivity, in order to allow calculation of the bioactivity of the sample. But this is no disadvantage, as the EPO samples should anyway routinely be measured against a reference substance (currently "Erythropoietin for physicochemical tests CRS batch 1" [15]), which should allow to precisely and accurately monitor the bioactivity and the quality of the EPO medicinal products via the I-number and/or Ibio-number assay.

\section{Conclusion}

The data presented in this retrospective analysis by the author of the CZE data of various (c)BRPs and the cCRS has shown that the Ibionumber assay enables assessment of the potency of EPO reference preparations with high precision and accuracy, paralleling and confirming the results obtained with the I-number assay [11]. Thus, the very broad criteria for EPO identification via CZE according to the $\mathrm{Ph}$. Eur. [7] (which is based on broad ranges defined for the various EPO isoforms) could be replaced by a single and quite narrow Ibionumber range, which would provide a significant increase in assay precision and accuracy and hence in drug safety. Moreover, the Ibionumber assay could be a candidate physicochemical assay to replace the mouse bioassay in the quality control of EPO batch release.

\section{References}

1. Storring PL, Gaines Das RE (1992) The international standard for recombinant DNA-derived erythropoietin: collaborative study of four recombinant DNA-derived erythropoietins and two highly purified human urinary erythropoietins. J Endocrinology 134: 459-484.

2. Hermentin P, Witzel R, Schwick-Wagner P, Blumrich M (2002) N-glycan charge assay - an alternative for potency assays of therapeutic glycoproteins?. Developments in Biologicals 111: 89-97.
3. Zimmermann H, Gerhard D, Hothorn LA, Dingermann T (2011) An Alternative to Animal Testing in the Quality Control of Erythropoietin. Pharmeuropa Bio\&SN 1: 66-80.

4. Barth T, Oliveira PR, D'Avila FB, Dalmora SL (2008) Validation of the normocythemic mice bioassay for the potency evaluation of recombinant human erythropoietin in pharmaceutical formulations. J AOAC Int 91: 285-291.

5. Bristow A (2008) Possible approaches for replacement of erythropoietin in vivo potency assay. In: EDQM, editors. Alternatives to animal testing: New approaches in the development and control of biologicals. Proceedings of the International Symposium, France 87-92.

6. Hermentin P (2017) Ibio-number assay: A physicochemical assay that predicts the bioactivity of erythropoietin with high precision and accuracy and may replace the mouse bioassay in the quality control of EPO batch release. Pharm Anal Acta 8: 533.

7. (2017) Erythropoietin concentrated solution, monograph 1316, Ph. Eur. 9.0. Strasbourg, France, Council of Europe, 2391-2395.

8. Hermentin P (2009) Method for characterizing the glycosylation of sialoglycoproteins via an isoform number I. EP 1943524 B1.

9. Hermentin P (2012) Method for characterisation of the quality of sialoglycoproteins via an isoform number I. US 8,150,630 B2.

10. Hermentin $\mathrm{P}$ (2006) Isoform number I - a new tool to evaluate the quality of erythropoietin. Pharmeuropa Scientific Notes 1: 37-40.

11. Hermentin P (2017) Evidence that the potencies of the biological reference preparations batch 1 and batch 2 of erythropoietin have been stated $\sim 5 \%$ too low respectively $\sim 10 \%$ too low (submitted).

12. (1997) Collaborative study for the establishment of a biological reference preparation for erythropoietin. Pharmeuropa Bio 2: 31-48.

13. Behr-Gross ME, Daas A, Bristow AF (2004) Collaborative study for the establishment of erythropoietin BRP Batch 2. Pharmeuropa Bio 1: 23-33.

14. Behr-Gross ME, Daas A, Burns C, Bristow AF (2007) Collaborative study for the establishment of erythropoietin BRP batch 3. Pharmeuropa Bio 1: 49-66.

15. Burns C, Bristow AF, Buchheit KH, Daas A, Wierer M, et al. (2015) Establishment of the Ph. Eur. erythropoietin chemical reference substance batch 1. Pharmeuropa Bio\&SN 2: 99-117.

16. Burns C, Bristow AF, Daas A, Costanzo A (2015) Collaborative study for the establishment of erythropoietin BRP batch 4 . Pharmeuropa Bio\&SN 2: $246-253$.

17. (2012) 3rd WHO International Standard for Erythropoietin, recombinant, for bioassay; NIBSC code: 11/170; Instructions for use.

18. Strickland TW, Byrne TE, Elliott SG (1996) Erythropoietin isoforms. EP 0 428267 B1.

19. Burg J, Sellinger KH, Haselbeck A, Koll H (2014) Erythropoietin with high specific activity. EP $1037921 \mathrm{~B} 1$.

20. Grubbs F (1969) Procedures for detecting outlying observations in samples. Technometrics 11: 1-21.

21. Dixon WJ (1950) Analysis of extreme values. Ann Math Stat 21: 488-506.

22. Zhang J, Chakraborty U, Villalobos AP, Brown JM, Foley JP (2009) Optimization and qualification of capillary zone electrophoresis method for glycoprotein isoform distribution of erythropoietin for quality control laboratory. J Pharm Biomed Anal 50: 538-543.

23. (2002) Erythropoietin concentrated solution, monograph 1316, Ph. Eur. 4.0. Strasbourg, France: Council of Europe, 1123-1128.

24. (2008) Erythropoietin concentrated solution, monograph 1316, Ph. Eur. 6.0. Strasbourg, France: Council of Europe, 1813-1817.

25. Williams RP, Bristow AF, Hauck WW, Srinivasan VS, Morris T, et al (2014) Role of Public Standards in the Safety and Efficacy of Biologic Medicines. AAPS J 16: 516-521.

26. van Aerts LAGJM, de Smet K, Reichmann G, van der Laan JW, Schneider CK (2014) Biosimilars entering the clinic without animal studies. A paradigm shift in the European Union. mAbs 6: 1155-1162.

27. Hermentin P (2017) I-number assay - a physicochemical assay that predicts the bioactivity of EPO samples: Proof of principle (submitted). 